\title{
Not if, but how: one way to talk with patients about forgoing life support
}

\author{
Rurik Löfmark, Tore Nilstun
}

\begin{abstract}
Summary
May the common clinical conversation be used to explore whether or not seriously ill patients want to talk about possible limitations of life support? In order to answer this question, a series of 20 seriously ill patients took part in an interview. The clinical conversations were taped and transcribed, and recurrent themes were identified and organised into categories. After talking about their diagnosis and prognosis, most patients said it was natural to talk about possible limitations of life support, and a substantial number immediately indicated that they did not want any life-sustaining treatment. Although their emotional reactions were different, no one seemed to be upset by talking about such issues. Many but not all patients said that they wanted a family member and possibly also a nurse to participate in the conversation. Every doctor learns to conduct a clinical conversation and this approach may be applied when talking with seriously ill patients about difficult treatment decisions.
\end{abstract}

Keywords: resuscitation decisions; clinical conversation

Professional guidelines in Sweden and in Europe recommend physicians to inform their patients about their diagnosis, prognosis and

Submitted 21 May 1999 Accepted 12 July 1999 treatment options. ${ }^{12}$ These recommendations also apply to patients at the end of life, for instance, when a Do-Not-Resuscitate (DNR) decision is to be made. However, studies have shown that less than half of the patients were informed of their DNR order, despite the fact that they were able to communicate and competent to understand. ${ }^{3-5}$

One reason often used by physicians to avoid talking with patients about limiting life support, especially DNR, is that it will harm the patient. ${ }^{67}$ The risk of harm may of course be real in some situations. However, a more plausible explanation is that many physicians do not know how to talk about such issues. This explanation is also in line with Stewart's proposal that "ideally, experienced clinicians should undertake such discussions . . . to determine how much the patient wishes to get involved".

The aim of this study was to test whether or not the common clinical conversation may be used to explore whether or not seriously ill patients want to talk about possible limitations of life support.

\section{Subjects and methods}

The setting was a department of general internal medicine with 108 beds in a secondary hospital. During a 4 -week period, 21 consecutively admitted patients were asked to take part in the study. The patients' diagnoses were known (table) and all were able to communicate. Three had a DNR order and the others fulfilled the criteria of serious illness, as indicated by the 'Prognosis-AfterResuscitation' (PAR) scale. ${ }^{9}$ A patient was regarded as seriously ill if he or she had six or more PAR points. At this level, there is almost no chance of surviving a heart stop, despite attempts at resuscitation.

An interview method close to a clinical conversation was used in order not to deviate from clinical practice (box). Patients were asked how they felt about taking part in such a conversation, and whether they wanted a relative and/or a nurse to be present. They were asked to describe how they experienced the interview, and their reactions were noted throughout the interview.

The patients were approached by one of the authors (RL), who presented himself as a research physician and informed them orally about the interview. They also received written information with the following questions: "Do seriously ill patients want to talk about their future 


\begin{tabular}{|l|}
$\begin{array}{l}\text { Themes in the } \\
\text { clinical } \\
\text { conversations }\end{array}$ \\
\hline - perception of the \\
situation \\
- thoughts about the \\
diagnosis \\
thoughts about the \\
prognosis \\
thoughts about \\
possible treatments \\
\hline
\end{tabular}

prospects? And if so, how?" The patients were informed that the interviewer was not responsible for their treatment, and that any questions regarding their clinical treatment would be directed to their attending physician, if they so wished. All but one of the patients agreed to participate. The interviews took place in a consultation room on the ward the following day. After permission from the patient, the interviews were tape recorded and transcribed verbatim within 48 hours. The length of the interviews varied between 20 and 45 minutes.

The study was approved by the regional ethical review board.

\section{Results}

The transcripts of the interviews were analysed. Recurrent themes were identified and organised into eight categories. ${ }^{10}$ These are used as headings in the presentation of the results.

PERCEPTION OF THE SITUATION

In the normal clinical setting, the first question asked is usually how the patient perceives his or her disease. Some of the patients in this study seemed to accept their fate. Typical responses were: "It's just right to wind up" (patient 2, table) and "I take each day as it comes" (patient 19). Other patients talked about the seriousness of their disease, but were composed: "I am old enough" (patient 6), "I have been so close to death" (patient 12) and "I am really bad now" (patient 15). There were also patients who stated that they did not wish to live any longer: "I am so incredibly lonesome" (patient 11), and "I have nothing more to live for" (patient 12). None of the patients hesitated to give his or her opinion of the situation and many of them were open to discuss lifesustaining treatment at the start of the conversation.

\section{THOUGHTS ABOUT THEIR DISEASE}

A few patients seemed to have a fairly good knowledge of their disease: "I've had one stroke and two heart attacks ... I have bad blood and goitre, and one of my kidneys is bad" (patient 12). However, some patients had inadequate knowledge of their disease and how serious it was: "So I was quite surprised" (patient 1) and "I have cancer in the kidneys, but it is not dangerous" (patient 14). Some patients knew very little about their disease: "I have not got any answers" (patient 15) and "They never tell you anything" (patient 19). As the diagnosis of each patient was clearly stated in their notes, it was surprising that their knowledge was not better. Only one patient, who had stated that she did not want to live any more, seemed to be sure of her diagnosis (patient 11).

THOUGHTS ABOUT THE PROGNOSIS

Most patients felt that the end was near: "My future prospects are non-existent" (patient 1), I will "hardly get out of here" (patient 4) and "God wants me at home" (patient 11). However, some patients were more optimistic: "You have to be positive ... and think that every- thing will be good" (patient 16) and "Oh no, I will not pass away now" (patient 20). A few patients were less sure about the future: "There must be some way out of this, but it is hard to get the strength back" (patient 7) and "I want to keep swinging, but I don't know" (patient 8). One patient misunderstood or avoided talking about the prognosis: "I ought to have better joints" (patient 3). The general impression was that most patients did not hesitate to talk about the future and seemed to have a fairly realistic understanding of the situation. They had far better knowledge about their prognosis than their diagnosis.

\section{THOUGHTS ABOUT TREATMENT}

Some patients were fully informed: "I need the dialysis three times a week" (patient 9), "I need medicine for the goitre before they will operate on my kidney" (patient 12). There were also patients with a poor knowledge about their treatment: "None that I've heard of" (patient 13) and "Yes, they took it away" (about the cancer which was 'killing' him) (patient 14). One patient stated that he did not want any treatment at all (patient 5). Another one was beside herself with the prospect of having to take cytotoxic drugs (patient 11). Only one patient had ever thought of cardiopulmonary resuscitation (CPR), which he wanted to receive if indicated. He was also the only one who seemed to know anything substantial about CPR (patient 8). None of the patients said that they had talked about CPR with his or her attending physician.

ATTITUDES TOWARDS TALKING ABOUT PROGNOSIS AND TREATMENT

Most of the patients wanted an open and straightforward discussion: "You ought to tell as soon as possible" (patient 1), "Just go on talking" (patient 2), "To talk is the only right thing" (patient 3), "It is the doctor's responsibility to tell" (patient 7), "I want a long and thorough discussion" (patient 11), "You should not sneak about it" (patient 15), "I think it's good" (patient 19) and "You should not keep it secret" (patient 20). A few patients believed talking might be too painful for others: "It's probably moving" (patient 2) and "Don't worry my wife" (patient 5). Only one patient said it was not a good idea to talk about his prognosis (patient 6). In summary, all but one of the patients wished to talk about their prognosis and treatment and the possible forgoing of treatment.

PARTICIPATION OF A FAMILY MEMBER

Some patients would accept a family member joining in the conversation: "Yes, absolutely" (patient 1), "Then they get to know what's the matter" (patient 15), "It might be good for them to listen" (patient 16) and "It would be good, but my wife will not join in. She's afraid of death" (patient 18). A few patients suggested that the physician should talk to the family alone: "Rather with my family than with me" (patient 3). Others hesitated: "My wife, yes, but you mustn't worry her" (patient 5), "It will be enough with the doctor I suppose" (patient 9). 
A few were not interested: "No, I think that you should talk in private" (patient 10). The reasons for participation varied, but no patient said that it would be solely for his or her own good.

PARTICIPATION OF A NURSE

Most patients wanted a nurse to participate in the discussion: "By all means. Together with my wife and children, perhaps" (patient 1), "Yes, why not, but no one else must decide" (patient 4), "Yes, my district nurse in that case" (patient 9) and "Why not, but you become attached to your doctor" (patient 18). Some were less certain: "Perhaps it might be good" (patient 16), "It doesn't matter" (patient 17); and others were negative, "It will be enough with the doctor" (patient 2) and "Which nurse? . . No, I don't have confidence in them at home" (patient 19). Some patients considered that his or her district nurse or deaconess was the best one to participate in such a discussion. No one named any of the attending staff nurses.

PATIENT EXPERIENCES OF THE CONVERSATION

Almost all patients were positive about the opportunity to talk about their future prospects: "This was the best talk I ever had" (patient 4), "I think you should talk with all patients in this way" (patient 5), "It feels easier now when you have been able to talk" (patient 12), "I think this was good, terribly good" (patient 16) and "Yes, it must be natural. Otherwise it won't work" (patient 20). Two patients thought it was difficult: "I became unhappy when talking about the cytotoxic drug" (patient 11). One patient avoided answering the questions. She said, "I become so terribly dry in my mouth" (patient 3). Most patients seemed to be relaxed when talking about their situation, but a few said that certain issues were difficult to discuss. For some of the patients, this became obvious to the interviewer at the beginning of the conversation (patients 3, 8, and 11).

PATIENTS' CONCLUDING REMARKS

At the end of the interview some patients introduced new issues: "There's just one thing missing ... A shot through the neck ... Ha ha!" (patient 6), "This was quite interesting, I think ...You can't go around thinking that you are the worst off ...Y You have to take each day as it comes" (patient 10), "Will you pray for me now?" (patient 11), "I'm very happy that you

1 Social Board of Health and Welfare. Life-sustaining treatment at the end of life (in Swedish). Stockholm: Allmänna Förlaget, 1992.

2 Doyal L, Wilsher D. Withholding cardiopulmonary resuscitation: proposals for formal guidelines. BMf 1993; 306:1593-6.

3 Asplund K, Britton $M$. Do-not-resuscitate orders in Swedish medical wards. F Intern Med 1990;228:139-45.

4 van Delden JJ, van der Maas PJ, Pijnenborg L, Looman CWN. Deciding not to resuscitate in Dutch hospitals. F Med CWN. Deciding not to

5 Löfmark R, Nilstun T. Do-Not-Resuscitate orders - should Löfmark R, Nilstun T. Do-Not-Resuscitate orders - shou
the patients be informed? F Intern Med 1997;241:421-5.

\section{Learning points}

- within a relatively short conversation, seriously ill patients easily accepted, and even valued, frank discussions about forgoing life support

- ask the patient about letting a family member and/or a nurse participate in the talk as such participation may not always be desired by the patient

- seriously ill patients are not generally harmed by talking about their prognosis

wanted to talk with me" (patient 19) and "I hope ... I long for home now" (patient 20).

\section{Discussion}

In this study we used a clinical conversation to identify different reaction patterns among typical DNR patients. Knowledge of such patterns enhances the physician's understanding of the individual patient and may also be instrumental in helping the patient to articulate his or her hopes and concerns. Whether the patterns of reactions identified can be generalised to other seriously ill patients has to be verified in other studies, as does the importance of the physician's communication skills.

In the presentation of the results, all patients have been directly quoted - some as many as eight times. However, neither the sampling frame nor the number of participants in the study is sufficient to allow any general conclusions to be drawn.

The clinical conversation method is an approach all physicians have learnt and one with which all patients are familiar. The structure of this method proved to be very successful. Within 10-20 minutes of conversation most patients seemed to be ready to talk about fundamental questions of life and death. It was also quite easy to get an idea of both the patient's values and his or her understanding of medical issues. For example, their knowledge about CPR was often very poor. When asked at the end of the interview, no one said that they had been troubled by the conversation itself. Many patients approved. They also emphasised that it is the doctors' duty to give such information to their patients. Most but not all welcomed the participation of a relative and a nurse. Thus, it might be a good idea to ask the patient if he or she really wants family members or a nurse to participate in such a discussion.

6 Schade SG, Muslin H. Do not resuscitate decisions: discussions with patients. F Med Ethics 1989;15:186-90.

7 Tobias JS, Souhami RL. Fully informed consent can be needlessly cruel. BM7 1993:307:199-201.

8 Stewart K. Discussing cardiopulmonary resuscitation with patients and relatives. Postgrad Med $\mathcal{F}$ 1995;71:585-9.

9 Ebell MH. Prearrest predictors of survival following in-hospital cardiopulmonary resuscitation: a meta-analysis. f Fam Pract 1992;34:551-8.

10 Fitzpatrick R, Boulton M. Qualitative methods for assessing health care. Quality Health Care 1994;3:107-13. 